\title{
Teaching the Whole Student: Integrating Wellness Education into the Academic
}

\section{Classroom}

\author{
Jeannine Johnson, Connie Bauman and Sarah Pociask \\ Wellesley College, Wellesley, United States
}

\begin{abstract}
College students are increasingly reporting higher stress, which can negatively influence their personal and intellectual development. Greater academic challenges and new social experiences in college may be accompanied by stressors like mental health issues, family concerns, or financial pressures. To help students manage stress, institutions typically provide resources through health services, student life or student affairs, recreation departments, or other entities that operates primarily outside the academic program. Recently, some institutions have integrated wellness education into the academic curriculum, leveraging the power of the classroom to deliver important lessons about accessible, evidence-based wellness strategies. Here we investigate if a first-year interdisciplinary writing class designed to help students learn about physical and mental wellbeing actually improved students' awareness of their wellbeing and their confidence as first year learners. We share details of the course design, evidence of student learning, and advice for incorporating wellness content throughout the curriculum.
\end{abstract}

Keywords: Wellbeing; mental health; first-year students; wellness programs; curriculum; writing instruction.

\section{Introduction}

Recent research on the health of college students highlights significant challenges that many of them experience throughout their time in school. In a national survey conducted by the American College Health Association (ACHA), students were asked about aspects of their life that have affected academic performance. The leading responses were stress, anxiety, sleep difficulties, and depression (American College Health Association, 2018). A majority of students also reported feeling overwhelmed or exhausted (not from physical activity) during the past year, and over half reported feeling hopeless, lonely, sad, or overwhelmingly anxious. These figures were even higher for female students. Similarly, a recent international study of college student health found that as many as one in three first-year students reported mental health issues in the past year; these issues, concerning in themselves, were also associated with reduced grades (Bruffaerts et al., 2018).

For first-year students, the experience of stress can be compounded by anxiety associated with their transition to college. A recent study found that first-year students tend to experience multiple challenges simultaneously, and managing their time, workload, and others' expectations were among the most prominent and prevalent (Brooker, Brooker, \& Lawrence, 2017). Moreover, the challenges of the first year can be especially pronounced for students who are from typically underrepresented groups, are from low income families, or are first-generation (Covarrubias, Gallimore, \& Okagaki, 2018; Kinzie, Gonyea, Shoup, \& Kuh, 2008; Terenzini et al., 1994). For many students, worries about debt and future employment opportunities are

This work is licensed under a Creative Commons Attribution 4.0 International Licence. As an open access journal, articles are free to use with proper attribution. ISSN: 2205-0795 
more prevalent than ever, and when students do not engage in coping strategies that help manage this stress, research suggests that they are at higher risk for experiencing depression and anxiety (Mahmoud, Staten, Hall, \& Lennie, 2012).

Given these circumstances, it is not surprising that many colleges and universities are seeing an increasing number of visits to their counseling services (Beiter et al., 2015). Likewise, there has been an increase in demand for more - and more inclusive services, programs, and amenities that support student wellness (Strand, Egeberg, \& Mozumdar, 2010). These kinds of resources are typically provided by and located in extra-curricular divisions, such as health services, student life or student affairs, and recreation departments.

While more such co-curricular resources are valuable and needed, they can be further complemented by support for students within the curriculum, particularly in the realm of wellness education. Knowledge of coping skills and self-care can be critical to academic success, and, in recent years, a growing number of credit-bearing college courses have aimed to provide students with practical knowledge and skills related to health and wellness (Beauchemin, Gibbs, \& Granello, 2018; Choate \& Smith, 2003). For instance, a psychology professor at Yale University recently developed a course on happiness. It attracted recordbreaking interest from students, and it is now also offered as a MOOC (Shimer, 2018). Another example of a course that integrates student awareness of their own wellness with academic study comes from the University of St. Thomas in Minnesota, which offers an interdisciplinary undergraduate health course that combines the academic study of neuroscience with contemplative practice, specifically yoga (Wolfe \& Moran, 2017).

Medical schools, too, are recognizing the value of teaching mindfulness to their students (Dobkin \& Hutchinson, 2013; Kraemer, Luberto, O'Bryan, Mysinger, \& Cotton, 2016). While the specific training approaches vary, medical programs have started to teach students how to be aware of the connections between thoughts, feelings, and behaviors. Learning practical skills like self-awareness, relaxation, and meditation can help medical students prevent the burnout that they frequently experience as they navigate the heavy workload and extensive responsibilities of professional training and their careers (Staffaroni, Ru sh, Graves, Hendrix, Haramati, \& Harazduk, 2017), and provide them with skills that they can pass on to future patients.

Early evidence from these curriculum-embedded approaches points to distinct advantages for enhancing student success both inside and outside the classroom. Building upon these examples, our study investigates if a first-year interdisciplinary writing class designed to help students learn about physical and mental wellbeing did actually improve students' awareness of their wellness and their confidence as first year learners. In the sections that follow, we share details of the course design, evidence of what students learned, and advice for others interested in incorporating wellness content throughout the college curriculum.

\section{Course Design and Approach}

At our institution all first-year students are required to take one writing course, which may be selected from among approximately 35 different theme-based offerings each year. Our course was designed as a required course, which distinguishes it from many wellness-based courses that are offered as electives, or as part of an additional curricular or co-curricular program. From 2016 to 2018, we offered a fall-semester, first-year writing course called Live and Learn: Understanding Mind-Body Connections. Enrollment ranged from 13 to 16 students, which is consistent with enrollments in other writing classes at our institution. The course was designed to teach writing and other scholarly skills while exposing students to historical and current understanding of the science behind mind-body connections, as well as the principles underlying contemporary wellness practices.

We created our course with the goal of supporting students in their transition to college, and providing them with practical, adaptive skills for coping with stress throughout their college career. Our aim was to improve first year students sense of wellbeing and confidence and enhance their sense of belonging to a community with the longer-term goals of fostering their future development as scholars and academic outcomes. The content and the design were organized largely around mindbody approaches that build stress resiliency, boost cognitive function, and promote overall physical and mental health. The course intended to engage students intellectually, emotionally, and physically, and it provided opportunities for experiential learning and direct application of course material. This broad-based approach to teaching the whole student derives from recognizing that intellectual pursuits don't exist in a vacuum, and that each person's intellectual potential is influenced by numerous factors. 
The class met for 70 minutes three times a week. Most first-year writing courses at our institution meet twice a week, but a third meeting was added to this course to allow for a weekly experiential learning lab. While we threaded wellness education throughout most class meetings, the labs provided students extra time to practice, reflect on, discuss, and assess wellness skills and integrate these lessons into their lives. Some labs were given over to practical application of course content. In other lab meetings, guest instructors led students in various forms of meditative practice (e.g., yoga, tai chi, sensory nature walks), led interactive workshops on nutrition, sleep, and other wellness topics, or introduced students to campus resources. Often, the space in which lab activities took place was different from our regular classroom.

Grant funding made it possible for us to purchase fitness equipment (e.g., yoga mats and stretch bands) and extra academic supplies (notebooks for activity journals) that students used during and outside class time. We also purchased health technology that allowed students to explore different types of meditative practices (through a subscription to the Headspace App) and to measure physiological processes (e.g., heart rate, sleep, and activity via Fitbit trackers). Through these tools, students could readily transport and apply the lessons of the class into their lives outside it. They then brought those experiences back into the academic sphere through writing assignments, presentations, discussion, and lab activities.

Six primary strategies were used to support teaching the whole student and meeting course goals. We were motivated to take advantage of knowledge and skills already familiar to students, and use that as a foundation on which to layer novel experiences and exploration in the course. We aimed to disrupt an inclination to compartmentalize experience, recognizing the profound influence of the emotional and physical spheres on intellectual development and academic achievement. Through these strategies, we were able to generate ready buy-in from students and enhance both their evolution as scholars and their personal growth.

1. Demonstrate the practical application of intellectual work. Two of the three main writing assignments required students to direct an evidence-based, audience-oriented argument toward a recommended course of action. Students also distilled what they learned about the science of wellness practices into four formal, small-group presentations, which they delivered to the president of our institution during a class visit. These exercises raised the stakes for student learning in a positive way, and their learning was enhanced by these opportunities to put new knowledge into practice.

2. Integrate goals for personal growth into the course curriculum. Students were asked to develop a personal wellness goal within the first two weeks, submitting a written plan that was subsequently revised. They periodically shared their goals with peers and regularly reported their progress to instructors. Peer and instructor support empowered students to attain personal goals and helped contribute to a sense of shared purpose in the class.

3. Build community. That shared purpose was also cultivated through community-building activities. In writing classes, it is typical to workshop drafts: when carefully managed, these workshops promote a shared sense of responsibility for the intellectual growth of the group, as well as for the classroom's social dynamic. Students also formed committees to work on projects outside class. These included the design of a class t-shirt, as well as efforts to apply wellness principles in activities in residence and dining halls, and at campus events. In addition, students wrote thank you cards for guest speakers in small groups. This latter, simple activity, repeated several times, promoted learning and community simultaneously: as students discussed what to include in the note, they shared their perspectives on what they learned from the guest presentation.

4. Recognize the influence of students' emotional states on class performance and intellectual growth. We made a concerted effort to arrive before the start of class and engage students in conversation about life (theirs and our own) outside the classroom. Judiciously sharing stories about our own experiences can enhance student motivation (Lang, 2016). Asking students about their interests outside class conveys collegiality and a genuine interest in what they bring to the classroom. These informal check-in conversations might be followed by a more structured discussion in which each student shared something that was on her mind (Parks, 2017). Sometimes, we began class with a brief breathing exercise, and periodically we took a break in the middle of class to restore mindfulness. These kinds of activities served as a kind of clearing of the emotional decks in preparation for (or a return to) serious intellectual work. We also made note of extra-curricular and recreation campus activities (e.g., boathouse yoga, peer-led recreation classes in barre and pilates) that could provide both fitness and social benefits to students. Time spent outside the class with peers contributed greatly to building friendships and support for behavioral change.

5. Recognize the influence of students' physical states on class performance and intellectual growth. Understanding that human attention is limited and that the typical sedentary position students occupy in the classroom can sap their energy, we incorporated movement breaks (of 1 to 5 minutes' duration) into the class. Usually occurring midway through class time, these 
breaks gave students an opportunity to stretch, change their posture, and observe the physiological changes (e.g., increased blood flow, heart rate, and oxygen levels) that result in increased attention. Students were more engaged following the activity break, which often led to more dynamic discussion. The breaks also served as a leadership opportunity, with each student leading a stretch or exercise break at least once during the semester.

6. Ask students to reflect on and shape the course of their own learning. In completing weekly wellness surveys, students were asked to reflect regularly on their day-to-day practices. We periodically shared (anonymously) some of these reflections, along with some of the data students reported. Students felt empowered by the fact that they were generating data worthy of study, and discussing these data promoted student survey adherence. Writing assignments were also designed to give students a degree of choice in their topic, and this often meant students were engaged with issues that deeply resonated with them. We found, as others have, that when students see their coursework as relevant to their own experience, their investment in the work increases considerably.

\section{Assessment of Student Learning}

For the purposes of this paper, we focus on quantitative and qualitative data collected from students during the Fall 2018 iteration of this course. Thirteen female, first-year students (average age $=17.69$ years old) were enrolled in the course. The quantitative data consisted of two surveys which were completed by students at the beginning (Week 1) and end (Week 12) of the semester: 1) a survey about attitudes and behaviors related to wellness and lifestyle habits to assess their wellness awareness and 2) a survey about familiarity with a selection of course concepts to assess their levels of confidence. There were multiple sources of qualitative data which included students wellness journals in which they documented sleep patterns, meditation, exercise, nutrition, and time management. The students also recorded how any exercise or meditation that they engaged in impacted their mood and cognition, and they logged any other comments or reflections they had that were related to the course material and personal wellness habits. Additional sources of qualitative data included students' comments in their final reflective writing assignment and in course evaluations.

According to federal guidelines, this study was exempt under Exemption Category 1: research on educational instructional strategies in regular educational settings. As such, our institutional review board did not require formal review for this work. Nonetheless, students were informed of the instructors' educational research interests with respect to the course, and they all provided informed consent to participate.

\section{Survey of Course Concepts}

Twelve students completed the beginning (Week 1) and end (Week 12) of semester surveys about their familiarity of course terms, and 11 students completed the surveys at both time points. Looking at the beginning and end of semester responses, students correctly identified more course terms at the end of the semester as compared to the start of the semester (Figure 1). This finding indicates that students familiarity of the course information increased during the semester.

\section{Figure 1}

Average Percentage of Correctly Identified Course Terms

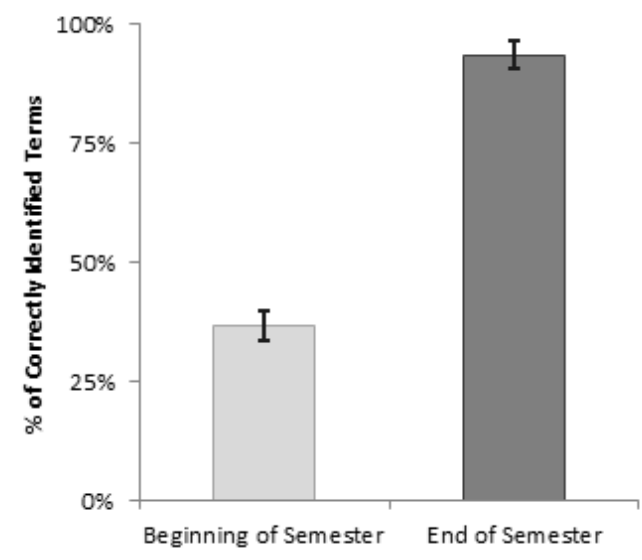




\section{Lifestyle Survey}

The lifestyle survey addressed a variety of aspects of student health and wellness, including sleep, meditation, exercise, nutrition, and time management. Twelve students completed the beginning and end of semester lifestyle surveys at both time points.

With respect to sleep, students reported feeling rested on a greater number of days at the end of the semester as compared to the beginning of the semester, and there were no changes in the number of days that students had difficulty sleeping. Substantial gains were also observed with meditation, as students increased the frequency that they meditated from less than 1 to about 3 days per week by the end of the semester. Students reported high levels of exercise at the start of the semester (on average, 4 to 5 days per week), and this remained consistent. A summary of these observations can be found in Figure 2. Students reported greater awareness of sugar consumption over the course of the semester, and gains were also observed with awareness of how to assess fitness (Figure 3). Student perceptions of their time management skills and balance between various daily commitments and responsibilities also improved (Figure 4).

\section{Figure 2}

Average Weekly Sleep and Exercise Ratings

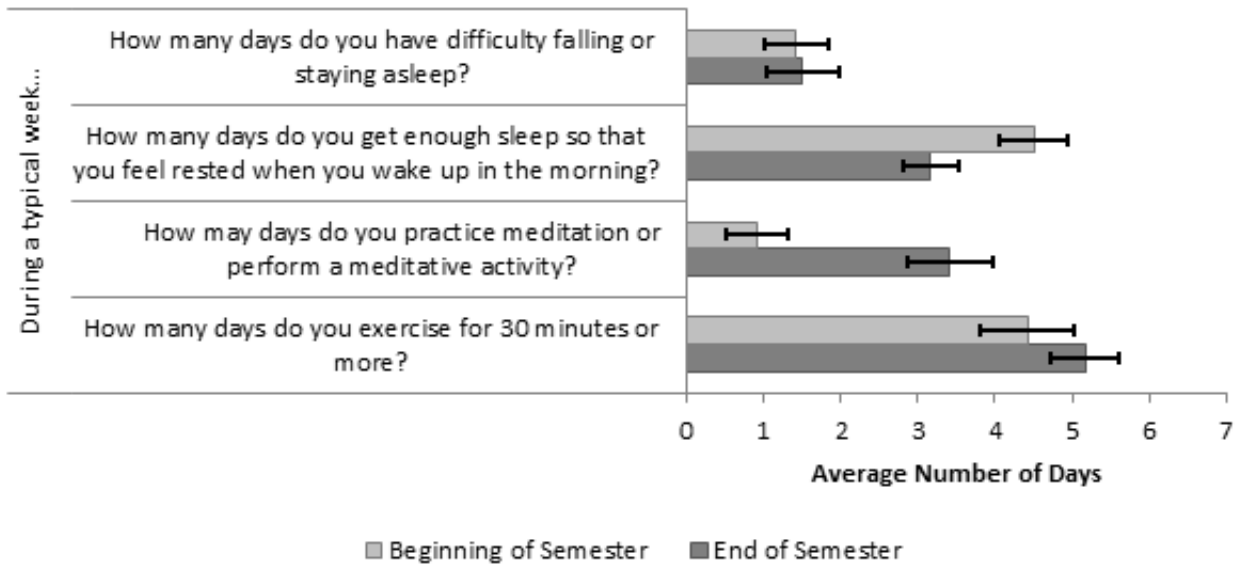

\section{Figure 3}

Self-reported Awareness of Sugar Consumption and Fitness Assessment

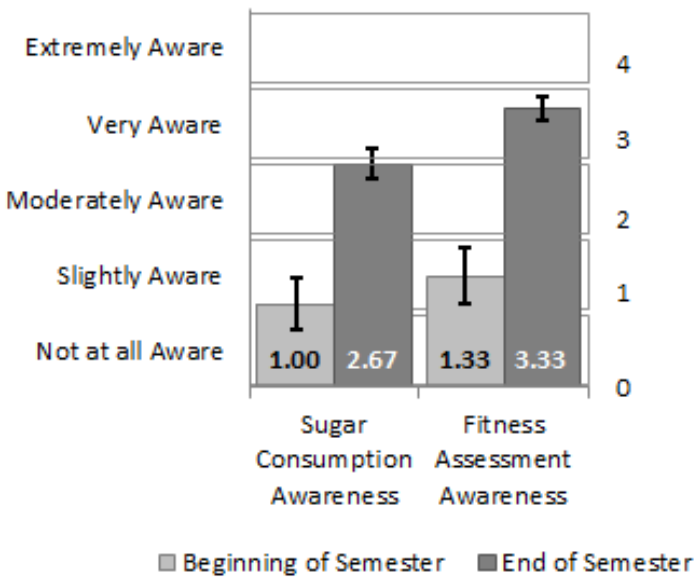




\section{Figure 4}

Self-reported Balance and Time Management

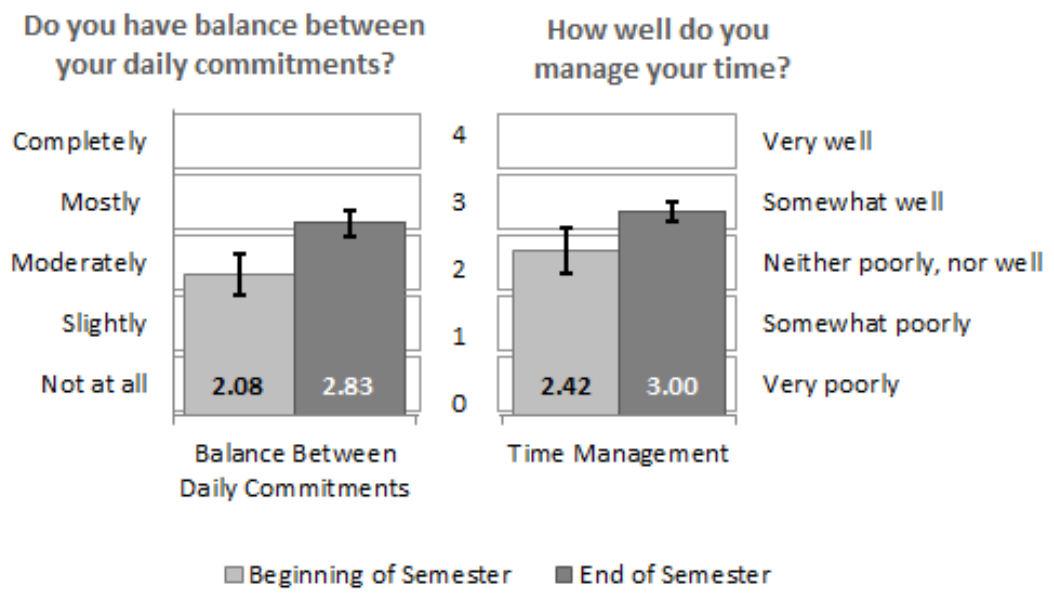

\section{Wellness Activity Journal Trends and Observations}

Students were instructed to complete an entry in their Wellness Activity Journal at least once per week for 13 weeks. This task served as a low-stakes way for students to reflect regularly on their wellness activities and goals. On average, responses were submitted by 11 students each week. Over the course of the semester, students completed a total of 142 responses, translating to 11 total journal entries on average per student.

In each journal entry, students reported their resting heart rate, hours of sleep the previous night, minutes of exercise and meditation on the day of the entry, and perceived changes in mood and cognition following any exercise and/or meditation. To highlight a few broad trends in these data (which are largely consistent with the results of the beginning and end of semester Lifestyle Survey): reported hours of sleep and minutes of meditation gradually increased over the course of the semester, and minutes of exercise remained fairly consistent and surprisingly high throughout the semester (90 minutes on average on journal entry day).

There was also space in the journal for students to include qualitative notes on wellness, and $70 \%$ of student journal entries included a reflective comment. Most frequently, students reflected on their physical activity or exercise (56\% of entries mentioned this topic) and how it made them feel, followed by sleep (34\%). Table 1 shows a complete summary of the wellness topics students addressed in their reflections. 
Table 1

Key Themes Observed in Student Wellness Journal Entries

\begin{tabular}{|c|c|c|}
\hline Wellness topic & $\begin{array}{l}\text { \% of Journal entries } \\
\text { that mentioned this } \\
\text { theme }\end{array}$ & Select quotes \\
\hline $\begin{array}{l}\text { Physical activity or } \\
\text { exercise }\end{array}$ & $56 \%$ & Exercising at night made me extremely alert. \\
\hline Sleep & $35 \%$ & Sleeping more really helps me focus. \\
\hline Meditation & $21 \%$ & $\begin{array}{l}\text { I need to implement meditation into my schedule as I would a } \\
\text { workout/class and make it a routine! }\end{array}$ \\
\hline Heart rate & $18 \%$ & $\begin{array}{l}\text { It's getting colder outside and I have noticed that my heart rate is } \\
\text { increased when I'm outside. }\end{array}$ \\
\hline $\begin{array}{l}\text { Time management/ } \\
\text { Life balance }\end{array}$ & $6 \%$ & $\begin{array}{l}\text { I have also noticed that as I continue to try yoga out two to three } \\
\text { times each week, I have become more productive with my } \\
\text { academics and my social life. }\end{array}$ \\
\hline Nutrition & $3 \%$ & $\begin{array}{l}\text { Trying to cut back on sugar this week and eating more vegetables, } \\
\text { because sugar usually makes me feel gross. }\end{array}$ \\
\hline
\end{tabular}

Throughout the course, students had many opportunities to share their thoughts about activities, assignments, and their experiences. Here, we share select representative comments gathered from three sources -the wellness journals, a required final reflection writing assignment, and course evaluations-that center around the achievement of key course learning goals.

\section{Building a Sense of Community}

Relating to the goal of creating a connected, supportive learning community, one student declared, "The class was one of a kind because it had its own community within it. The course taught us about how to take care of ourselves and each other." Similarly, another student affirmed that "I enjoyed gaining knowledge about healthy living as well as experiencing a whole class full of people that care about your wellbeing." These comments point to the value students placed in learning about wellness, and also in supporting each other as they engaged in this learning. One even seemed to anticipate that there will be an ongoing value from the course, remarking, "I would recommend this course because the relationships and lessons are long lasting."

\section{With Longer Term Goals in Mind}

Students also enjoyed the applicability of the content covered in this course, and how the knowledge and skills would not only benefit them currently in their transition to college, but also throughout their remaining college years and beyond. For example, one student noted, "I appreciated how relevant this course was to our everyday life and how so many things we learned were applicable to leading healthy lives. I loved learning about ways to cope with stress, as well as studying the mechanisms behind stress responses." Another student observed, "This class provided me with the resources to improve my life both mentally and physically. Because of this class, I work out every week and am more aware of why I am stressed and how I can address the stress." One comment spoke to the impact of the course on the student's academic success, as well as to the benefit of taking this course in her first semester: "This course allowed me to learn valuable techniques to stay healthy and be successful in other academic areas. Also, the class helped me adapt to college." Finally, a student underscored the important interplay between personal and intellectual growth in offering this advice to future students: "This class allows you to ... change as an individual, so ... take every lesson, reading, and paper seriously." 


\section{Increased Awareness of the Importance of Wellness}

Of all the wellness practices students learned and implemented in the course, meditation (including breathing exercises) emerged as the one in which they progressed most. This is likely due to the fact that students were not familiar with most forms of meditation at the beginning of the term, allowing for the greatest room for development in that area. With practice and experience came some positive results. For instance, one student reported on her use of meditation to improve activities in the academic sphere: "I did a writing meditation before a math quiz today to help calm myself. I think it definitely helped me focus during the test." Her experience reflects the findings of a recent study on meditation and short-term boosts in learning (Lin \& Mai, 2018). Another student shared, "Practicing meditation outside the classroom is what I enjoyed the most. I incorporated the mindfulness meditation techniques into my lifestyle to manage stress and overall give me a better quality of life." A study by Oman, Shapiro, Thoresen, Plante and Flinders (2008) affirms this perception that meditation can be an effective way for college students to reduce their sense of stress.

Some students held prior misconceptions about meditation that this course helped to dispel, as this statement indicates: "I learned that meditation and mindfulness, similar to physical activity, should be integrated into your daily life. Before this class, I thought of meditation as a very daunting task. Now I know that it doesn't have to be and that simply being aware of your thoughts can be a form of meditation." In addition, students started making connections between meditation and other aspects of wellness, such as sleep: "Meditation has helped me to achieve better quality sleep. My Fitbit app has confirmed that I am sleeping more and that my sleep quality has been improving steadily. I feel a lot more energized and productive with more sleep."

As these reflections suggest, overall the class was successful in developing students' sense of a complementary relationship between the physical, emotional, and intellectual realms, and in demonstrating the advantages of constructing a classroom teaching approach oriented to the whole student. Indeed, one student attested that the class "was a great balance of fun, writing, and promoting a healthy lifestyle. I started sleeping so much more, being more conscious about what I eat, and even joined a sports team because of this course. In addition, my writing in general feels better, and I am much more confident."

\section{Discussion}

Assessment data from this course indicate that educating students about wellness practices led to improved awareness of these topics and how they contribute to overall health and wellbeing, as well as to positive behavior changes. Informed by the scholarly activities of their reading, writing, research, presentations, and class discussion, and inspired by experiential learning in lecture and lab, students developed wellness habits that promote and enrich physical and mental health, stress resilience, and a positive transition to college. These findings are consistent with observations from other classroom-based wellness interventions (for a review see, Beauchemin et al., 2018), which have noted improved knowledge of wellness concepts (McCormick \& Lockwood, 2006; Wolfe \& Moran, 2017), improved awareness of nutrition (Choate \& Smith, 2003; Lockwood $\&$ Wohl, 2012), and improved sleep habits (Caldwell, Harrison, Adams, Quin, \& Greeson, 2010), among other outcomes.

In addition to exisiting reports, we found that developing community and a sense of belonging are important to encourage student investment in the course and to improve their learning outcomes. Through the shared experience of class, and through group discussions of personally relevant content and experiences, students developed meaningful connections with their peers and became collectively engaged and invested in the course and each other. A growing understanding of the importance of belonging and increased feelings of belonging were also observed by Higgins, Lauzon, Yew, Bratseth and Morley (2009) in their study of student reflections at the end of their own wellness course. Students' sense of belonging is an important aspect of their overall wellbeing on campus (Strayhorn 2012; Walton \& Cohen, 2007), and we can cultivate it through the work we do in the classroom.

As evidenced in our student reflections, there was tremendous growth centered on wellness, particularly around realizations of existing wellness habits, areas for personal growth, and a new-found value for physical and emotional health. An especially encouraging finding from our students was an overwhelming affirmation of the wide-ranging uses of different forms of meditation, the physiological bases of which are starting to be illuminated by emerging science (Chen et al., 2012; Creswell et al., 2016; Eyre et al., 2016). 


\section{Reflections on the Course}

To create time for some of the community-building activities, we had to reduce time spent on course content. This compromise was mitigated but not obviated by the fact that we added an extra class session per week. Despite the need to compromise on the class-time delivery of some material, we believe that this investment ultimately leads to better academic outcomes because it empowers students, creates more buy-in, and increases their investment in and commitment to the class. Student evaluations and feedback were significantly positive on social support from their peers and instructors. Deliberately providing positive community experiences within an academic class--especially in the first semester of college--creates a strong foundation for future personal and academic success.

We do admit some trepidation in opening the door to parts of students' personal lives, as we were concerned that in so doing we might be signalling that our class was less intellectually demanding or less sophisticated or serious than others. However, emotion is always an influence on students, whether we acknowledge this fact or not. While emotion can be distracting to students, it is possible to harness it to help direct the "spotlight" of students' attention to the course material (Cavanaugh, 2016). In fact, research suggests that helping students process emotions experienced in the classroom can improve performance on tests and other assessments (Beilock \& Ramirez, 2011).

If we were to teach the course again, we would place even more emphasis on meditation and reduce content and time given over (especially in the first part of the course) to the topic of physical activity as a stress-mitigating tool. The majority of the students were already physically active and generally aware of the benefits of exercise. Based on these early survey findings, we could have introduced meditation and mindfulness sooner than we did. Doing so may have helped students address the social and academic stressors that are especially high in a new college environment. Moreover, this approach would have given students more time to explore different types of meditation and to have more opportunities to practice those that resonated with them. We would also revise the weekly surveys to always require some reflection or other qualitative comments, and we would try to implement incentives so that students would complete them more consistently.

\section{Applications of the Course}

Our course is one of a growing number of classes explicitly focused on wellness as an intellectual subject and featuring experiential learning. It is somewhat unique in that it is directed specifically to first-year students via a required course, and it could be replicated at other institutions that also offer theme-based first-year writing courses or first-year seminars. But our approach can be scaled down and its elements integrated into almost any course in any discipline for students of any class year. We offer the following suggestions, grouped first into those that focus on mind-body connections, and then into those that can foster in-class community.

With minimal planning, faculty could easily include brief (1- to 2-minute) breaks during most classes for mindful breathing or light stretching exercises. Although these activities might be considered by some to be disruptive or antithetical to the scholarly nature of the class, they may in fact lead to more intellectually productive class sessions. It has been well-established that students' attention wavers during long classes (Bunce, Flens, \& Neiles, 2010; Szpunar, Moulton, Schacter, 2013), and attention may be effectively re-set with a brief break. Similarly, faculty might combine physical movement and intellectual work by devising or modifying a lesson so that students must leave their seats or positions. Movement of varying types has been tied to improved learning outcomes at the primary, secondary, and tertiary levels (Doyle \& Zakrajsek, 2018; Jensen, 2005). Students might be asked to use the board or poster-size sticky notes for any number of formal or informal activities; or they might be asked to move to a different part of the room for--or to stand during--paired or small-group work.

We also recommend that faculty carve out a small portion of class (such as at its beginning or end) for check-ins with students: forging connections in this way is likely to compensate for any sacrifice of class time. Furthermore, faculty can easily integrate their own stories into lecture or discussion, and doing so might provide a strong emotional pathway to students' intellectual growth (Cavanaugh, 2016). We likewise suggest that faculty invite other faculty, staff, or alumni to a class to share their own experiences with students, especially as they relate to the course. Finally, faculty might include short (e.g., 5-minute) wellness modules that are relevant to their course content and goals. The class might watch a short video, discuss a brief reading, perform an activity, or develop a goal and plan related to sleep, nutrition, exercise, time management, and the like. Developing such modules, especially ones that are easily transportable to a variety of disciplines and courses, is something that we are in the process of doing at our institution. 


\section{Design Limitations and Future Directions}

While we were able to observe evidence that students learned the wellness content and skills, and experienced success in applying these skills in other areas of their first-year college experience, additional work is needed to understand the impact that a course like this has on students. In the present study, the class size was small $(\mathrm{N}=13)$, and students chose to enroll in the course, so further research with a greater number of students, and more variability in topic interest, will add to our understanding of how to effectively support student learning of wellness. With respect to the assessment data, students were given the opportunity to choose when they submitted their journal entries, and some students did not report their wellness data consistently on the same day of each week. To improve the quality and representation of the wellness journal data, future studies might consider a random time sampling approach, where students receive the prompts for wellness journal entries on random days throughout each week or throughout the term.

In addition, we acknowledge that further evaluation of the impact of our course design is dependent on replicating it (at our institution and elsewhere), and we recognize that there are some challenges inherent in trying to do so directly. For example, for the course design described in this study, we received extra funding from various sources to purchase supplies and equipment for the class, as well as pay for assessment of it. Faculty at other institutions may not have access to such funding, and as such, modifications to the technology and resources included in the course will need to change depending on what is feasible. Similarly, we realize that faculty elsewhere may otherwise not be equipped, or may lack the authority, to create and offer a new course in a way that would allow it to be reproduced as reported in this paper. Despite these limitations, we feel that the main principles of the class are portable and scalable to a wide range of courses in various disciplines and at different types of institutions; and we believe that broad, conceptual replications will help with the advancement of student success in terms of academic achievement and wellness.

Future studies might consider following students for a longer period of time, preferably through their senior year or even beyond graduation, to determine if their newly developed wellness skills continue to be applied and cultivated. In addition, studies are needed to test links between wellness practices and academic achievement directly. We did not compare student academic performance, stress, or wellness knowledge or habits in this class to other first-year students, and this comparison would offer additional information about the extent to which students gain from the experience of curriculum-based wellness education, particularly if done longitudinally.

\section{Conclusion}

It is critical that students receive messages about wellness from, and can look for models of healthy behavior in, individuals and resources located not just in extra-curricular spheres but within the academic program at their institutions. Using data collected from previous ACHA surveys, researchers have found positive associations between academic performance and adherence to public health recommendations related to sleep, exercise, and nutrition. However, possibly due in part to insufficient wellness education, most college student respondents did not meet these health goals (Wald, Muennig, O'Connell, \& Garber, 2014). With this in mind, we designed a first-year writing course that aimed to embed wellness education within a class that fulfills an academic requirement. Our approach may be reproduced at smaller scale in courses of varying style, size, and discipline. The college classroom is well-positioned to deliver lessons about wellness and about stress management in general, and to provide a space for students to practice putting that knowledge to use. In this way, faculty might help more students achieve health and wellbeing goals, and, thereby, also improve their academic experience.

\section{Acknowledgements}

This project was supported by an internal institutional grant from the Andrew W. Mellon Foundation for evidence-based teaching innovations. Fitbit trackers were generously donated by Amy Batchelor. We also want to acknowledge our research assistant, Beryl Larson, for her invaluable support with data management and assessment throughout the duration of this project. 


\section{References}

American College Health Association. (2018). American College Health Association-National College Health Assessment II: Undergraduate Student Reference Group Executive Summary Spring 2018. American College Health Association. https://acha.org

Beauchemin, J., Gibbs, T., \& Granello, P. (2018). Wellness promotion courses in university settings: A review of the outcome research. Building Healthy Academic Communities Journal, 2(1), 36-49. https://doi.org/10.18061/bhac.v2i1.6344

Beiter, R., Nash, R., McCrady, M., Rhoades, D., Linscomb, M., Clarahan, M., \& Sammut, S. (2015). The prevalence and correlates of depression, anxiety, and stress in a sample of college students. Journal of Affective Disorders, 173, 90-96. https://doi.org/10.1016/j.jad.2014.10.054

Beilock, S. L., \& Ramirez, G. (2011). On the interplay of emotion and cognitive control: Implications for enhancing academic achievement. In Psychology of Learning and Motivation, 55(2011), 137-169. https://doi.org/10.1016/B978-012-387691-1.00005-3

Brooker, A., Brooker, S., \& Lawrence, J., (2017). First year students' perceptions of their difficulties. Student Success, 8 (1), 49-62. https://doi.org/10.5204/ssj.v8i1.352

Bruffaerts, R., Mortier, P., Kiekens, G., Auerbach, R. P., Cuijpers, P., Demyttenaere, K., \& Kessler, R. C. (2018). Mental health problems in college freshmen: Prevalence and academic functioning. Journal of Affective Disorders, 225, 97-103. https://doi.org/10.1016/j.jad.2017.07.044

Bunce, D. M., Flens, E. A., \& Neiles, K. Y. (2010). How long can students pay attention in class? A study of student attention decline using clickers. Journal of Chemical Education, 87(12), 1438-1443. https://doi.org/10.1021/ed100409p

Caldwell, K., Harrison, M., Adams, M., Quin, R. H., \& Greeson, J. (2010). Developing mindfulness in college students through movement-based courses: effects on self-regulatory self-efficacy, mood, stress, and sleep quality. Journal of American College Health, 58(5), 433-442. https://doi.org/10.1080/07448480903540481

Cavanaugh. S. (2016). The spark of learning: Energizing the college classroom with the science of emotion. West Virginia University Press.

Chen, K. W., Berger, C. C., Manheimer, E., Forde, D., Magidson, J., Dachman, L., \& Lejuez, C. W. (2012). Meditative therapies for reducing anxiety: A systematic review and meta-analysis of randomized controlled trials. Depression and Anxiety, 29(7), 545-562. https://doi.org/10.1002/da.21964

Choate, L. H., \& Smith, S. L. (2003). Enhancing development in 1st-year college student success courses: A holistic approach. The Journal of Humanistic Counseling, Education and Development, 42(2), 178-193. https://doi.org/10.1002/j.2164-490X.2003.tb00005.x

Covarrubias, R., Gallimore, R., \& Okagaki, L. (2018). "I know that I should be here": Lessons learned from the first-year performance of borderline university applicants. Journal of College Student Retention: Research, Theory \& Practice, 20 (1), 92-115. https://doi.org/10.1177/1521025116651635

Creswell, J.D., Taren, A. A., Lindsay, E. K., Greco, C. M., Gianaros, P. J., Fairgrieve, A., Marsland, A. L., Brown, K. W., Way, B. M., Rosen, R. K., \& Ferris, J. L. (2016). Alterations in resting-state functional connectivity link mindfulness meditation with reduced interleukin-6: A randomized controlled trial. Biological Psychiatry 80(1), 53-61. https://doi.org/10.1016/j.biopsych.2016.01.008

Dobkin, P. L., \& Hutchinson, T. A. (2013). Teaching mindfulness in medical school: where are we now and where are we going? Medical Education, 47(8), 768-779. https://doi.org/10.1111/medu.12200

Doyle, T., \& Zakrajsek, T. (2018). The new science of learning: How to learn in harmony with your brain. Stylus Publishing, LLC.

Eyre, H.A., Acevedo, B., Yang., H., Siddarth, P., Van Dyk, K., Ercoli, L., ... Lavretsky, H. (2016). Changes in neural connectivity and memory following a yoga intervention for older adults: A pilot study. Journal of Alzheimers Disease 52(2), 673-84. https://doi.org/10.3233/JAD-150653

Higgins, J. W., Lauzon, L. L., Yew, A., Bratseth, C., \& Morley, V. (2009). University students' wellness: What difference can a course make? College Student Journal, 43(3). https://link-gale-com

Jensen, E. (2005). Teaching with the Brain in Mind ( $\left.2^{\text {nd }} e d n\right)$. Association for Supervision and Curriculum Development.

Kinzie, J., Gonyea, R., Shoup, R., \& Kuh, G. D. (2008). Promoting persistence and success of underrepresented students: Lessons for teaching and learning. New Directions for Teaching and Learning, 2008(115), 21-38. https://doi.org/10.1002/tl.323 
Kraemer, K. M., Luberto, C. M., O'Bryan, E. M., Mysinger, E., \& Cotton, S. (2016). Mind-body skills training to improve distress tolerance in medical students: A pilot study. Teaching and Learning in Medicine, 28(2), 219-228. https://doi.org/10.1080/10401334.2016.1146605

Lang, J. (2016). Small teaching: everyday lessons from the science of learning. Jossey-Bass.

Lin, J. W., \& Mai, L. J. (2018). Impact of mindfulness meditation intervention on academic performance. Innovations in Education and Teaching International, 55(3), 366-375. https://doi.org/10.1080/14703297.2016.1231617

Lockwood, P., \& Wohl, R. (2012). The impact of a 15-week lifetime wellness course on behavior change and self-efficacy in college students. College Student Journal, 46(3), 628-641.

Mahmoud, J. S. R., Staten, R. T., Hall, L. A., \& Lennie, T. A. (2012). The relationship among young adult college students' depression, anxiety, stress, demographics, life satisfaction, and coping styles. Issues in Mental Health Nursing, 33(3), 149-156. https://doi.org/10.3109/01612840.2011.632708

McCormick, J., \& Lockwood, P. (2006). College student perception of wellness concepts. Physical Educator, $63(2), 78$.

Oman, D., Shapiro, S. L., Thoresen, C. E., Plante, T. G., \& Flinders, T. (2008). Meditation lowers stress and supports forgiveness among college students: A randomized controlled trial. Journal of American College Health, 56(5), 569-578. https://doi.org/10.3200/JACH.56.5.569-578

Parks, M. (2017, September). Simple strategies to develop rapport with students and build a positive classroom environment. National Teaching and Learning Forum, 26(5). https://doi.org/10.1002/ntlf.30122

Shimer, D. (2018, January 28). Easier taught than done? Yale's most popular class tackles happiness. New York Times. https://www.nytimes.com/2018/01/26/nyregion/at-yale-class-on-happiness-draws-huge-crowd-laurie-santos.html

Staffaroni, A., Rush, C. L., Graves, K. D., Hendrix, K., Haramati, A., \& Harazduk, N. (2017). Long-term follow-up of mindbody medicine practices among medical school graduates. Med Teach, 39(12), 1275-1283. https://doi.org/10.1080/0142159X.2017.1372562

Strand, B. N., Egeberg, J., \& Mozumdar, A. (2010). The prevalence and characteristics of wellness programs and centers at two-year and four-year colleges and universities. Recreational Sports Journal, 34(1), 45-57. https://doi.org/10.1123/rsj.34.1.45

Strayhorn, T. L. (2012). College Students' Sense of Belonging: A Key to Educational Success for All Students. Routledge.

Szpunar, K. K., Moulton, S. T., \& Schacter, D. L. (2013). Mind wandering and education: From the classroom to online learning. Frontiers in Psychology, 4, 495. https://doi.org/10.3389/fpsyg.2013.00495

Terenzini, P. T., Rendon, L. I., Upcraft, M. L., Millar, S. B., Allison, K. W., Gregg, P. L., \& Jalomo, R. (1994). The transition to college: Diverse students, diverse stories. Research in Higher Education, 35 (1), 57-73. https://doi.org/10.1007/BF02496662

Wald, A., Muennig, P. A., O'Connell, K. A., \& Garber, C. E. (2014). Associations between healthy lifestyle behaviors and academic performance in US undergraduates: A secondary analysis of the American College Health Association's National College Health Assessment II. American Journal of Health Promotion, 28 (5), 298-305. https://doi.org/10.4278/ajhp.120518-QUAN-265

Walton, G. M., \& Cohen, G. L. (2007). A question of belonging: race, social fit, and achievement. Journal of Personality and Social Psychology, 92 (1), 82. https://doi.org/10.1037/0022-3514.92.1.82

Wolfe, U., \& Moran, A. (2017). Integrating brain science into health studies: An interdisciplinary course in contemplative neuroscience and yoga. Journal of Undergraduate Neuroscience Education, 16(1), A77. https://www.ncbi.nlm.nih.gov/pmc/articles/ PMC5777842/

Please cite this article as:

Johnson, J., Bauman, C., \& Pociask, S. (2019). Teaching the whole student: Integrating wellness education into the academic classroom Student Success, 10(3), 92-103. https://doi.org/10.5204/ssj.v10i3.1418

This article has been peer reviewed and accepted for publication in Student Success. Please see the Editorial Policies under the 'About' section of the Journal website for further information.

Student Success: A journal exploring the experiences of students in tertiary education

(c) () This work is licensed under a Creative Commons Attribution 4.0 International Licence. As an open access journal, articles are free to use with proper attribution. ISSN: 2205-0795 